\title{
Diagnosis of mucosal changes and hospitalized oral cancer patients in Brazil: influence of socioeconomic factors
}

\section{Aldelany Ramalho FREIRE(a) Deborah Ellen Wanderley Gomes FREIRE(a)}

Gilberto Alfredo PUCCA JÚNIOR(b) Fernanda Campos de Almeida CARRER(c)

\section{Simone Alves de SOUSA ${ }^{(a)}$}

Edson Hilan Gomes de LUCENA(a) Yuri Wanderley CAVALCANTI(a)

(a) Universidade Federal da Paraíba - UFPB, Graduate Program in Dentistry, Department of Social Medicine and Dentistry, João Pessoa, PB, Brazil.

(b) Universidade de Brasília - UnB, School of Health Sciences, Graduate Program in Dentistry, Brasília, DF, Brazil.

(c) Universidade de São Paulo - USP, School of Dentistry, Department of Social Dentistry, São Paulo, SP, Brazil.

Declaration of Interests: The authors certify that they have no commercial or associative interest that represents a conflict of interest in connection with the manuscript.

Corresponding Author:

Yuri Wanderley Cavalcanti

E-mail: yuri@ccs.ufpb.br

https://doi.org/10.1590/1807-3107bor-2021.vol35.0042

Submitted: February 10, 2020

Accepted for publication: October 22, 2020

Last revision: Novembrer 17, 2020
Abstract: This study aimed to analyze the influence of socioeconomic factors on the frequency of diagnoses of oral mucosal changes and the number of hospitalized patients with oral and oropharyngeal cancer in Brazil. This cross-sectional study analyzed data from all Brazilian cities in the period 2011-2017. The frequency of diagnoses of oral mucosal changes and the number of hospitalized patients of oral and oropharyngeal cancer in Brazil were extracted from the Primary Care Information System (SIAB) and Brazilian National Cancer Institute (INCA) databases. The socioeconomic factors evaluated were the Gini coefficient of inequality, municipal Human Development Index (MHDI), inadequate basic sanitation rate, employment rate, illiteracy rate and expected years of schooling. Associated factors were examined using bivariate Spearman's correlations and multivariate Poisson regressions, and statistically significant $(\mathrm{p}<0.05)$ correlations between study variables and regression coefficients were obtained. A higher frequency of diagnoses of mucosal changes was observed in cities with a higher Gini coefficient $(B=11.614 ; p<0.001)$, higher MHDI $(B=11.298$; $p<0.001)$, and higher number of hospitalized patients with oral and oropharyngeal cancer $(B=0.001, p<0.002)$. Cities with higher Gini coefficients $(B=8.159, \mathrm{p}<0.001)$, higher inadequate basic sanitation rates $(B=0.09, p=0.001)$, lower expected years of schooling $(B=-0.718$, $p<0.001)$, and higher illiteracy rates $(B=0.191, p<0.001)$ had a higher frequency of hospitalized patients with oral and oropharyngeal cancer. In conclusion, more developed cities showed a higher frequency of diagnoses of mucosal changes. Greater inequality and worse socioeconomic conditions are associated with a higher frequency of hospitalized patients with oral and oropharyngeal cancer in Brazil.

Keywords: Mouth Neoplasms; Diagnosis, Oral; Socioeconomic Factors.

\section{Introduction}

Lip and oral cavity cancer is one of the most prevalent cancers worldwide; it was estimated to be the $16^{\text {th }}$ most common type of cancer in 2018. ${ }^{1,2}$ Oropharynx and salivary gland cancer lesions are also frequent and among the thirty most incident cases of cancer in Brazil. ${ }^{2}$ When considering lip, oral cavity, oropharynx and salivary gland cancer cases, Brazil has an age-standardized rate of 6.5 new cases per 
100,000 inhabitants. ${ }^{2}$ The incidence of the disease is higher for males and individuals over 60 years of age. ${ }^{3,4,5}$ In recent decades, however, there has been a reduction in the number of affected men compared to women ${ }^{3}$ as well as an increase in the number of cases among young adults younger than 45 years old..$^{4,6}$

Several factors are associated with the prevalence of oral cancer, including nonmodifiable factors (such as sex and age) and modifiable factors (lifestyle). ${ }^{5,7}$ Smoking and alcohol consumption are considered the main risk factors. ${ }^{8,9,10}$ Infection by human papillomavirus, solar radiation, immunosuppression and unhealthy eating habits are also relevant etiological factors. ${ }^{7,8,11}$ Furthermore, the literature reports the influence of environmental factors resulting from the social and economic contexts of individuals. ${ }^{12,13}$

Studies suggest that oral cancer is more prevalent among individuals exposed to unfavorable socioeconomic conditions and those living in socially disadvantaged areas marked by inequality ${ }^{8,12}$. Thus, socioeconomic vulnerability acts as a risk factor comparable to those related to lifestyle ${ }^{13}$. The difficulty in regular access to health care and the greater prevalence of smoking and alcohol consumption, poor nutrition and greater exposure to occupational risk factors may explain this relationship., ${ }^{8,12,14,15}$ Recognition of the important role of socioeconomic factors in the development of oral cancer in a population is essential for targeting intersectoral interventions and reducing cancer rates. . $^{13,16,17}$

Brazil is a developing country of continental size that is affected by social inequalities and a mixed population. Approximately $75 \%$ of the population is dependent on the public health system, but only $40 \%$ are registered for primary health care through the Family Health Strategy. ${ }^{18}$ Within the public healthcare sector in Brazil, measures are available for the diagnosis and treatment of cancer, but access to healthcare services is unequal. ${ }^{18,19,20}$

Given the above, the aim of this study was to analyze the influence of socioeconomic indicators on the frequency of diagnoses of oral mucosal changes and the number of hospitalized patients with oral and oropharyngeal cancer in Brazilian cities. This study also included analysis of factors associated with the frequency of hospitalization in those with cancer lesions in the following sites: lip and oral cavity (C-00 to C-06), salivary glands (C-07 to C-09) and oropharynx (C-10). Analysis of socioeconomic factors should contribute to the identification of risk factors, and such information can be used for adjusting public policies in Brazil as well as in other countries and populations.

\section{Methodology}

An observational, cross-sectional and ecological study was conducted for the period between 2011 and 2017. All Brazilian cities were included $(n=5565)$. The main outcome variables for this study were the number of diagnoses of mucosal changes in the Primary Care Information System (SIAB - http://tabnet.datasus. gov.br/cgi/deftohtm.exe?siab/cnv/siabobr.def) and the number of hospitalized patients with oral and oropharyngeal cancer according to the Hospital-Based Cancer Registry database of the Brazilian National Cancer Institute (INCA-HRC - https://irhc.inca.gov. br/RHCNet/visualizaTabNetExterno.action).

The number of diagnoses of mucosal changes was obtained from the national database of the SIAB, which is linked to the primary care services of the Brazilian public health system. The diagnosis of mucosal changes consists of a clinical procedure in which the dentist of primary care detects oral lesions during routine examination or during campaigns. According to the SIAB, mucosal changes can be nonneoplastic proliferative processes, benign neoplasms, malignant neoplasms, infectious diseases (bacterial, fungal or viral), mucocutaneous diseases and oral manifestations of systemic diseases. This variable represents the sum of individuals with oral mucosa changes between 2011 and 2015 for each municipality.

The sum of cases of oral and oropharyngeal cancer involving hospitalization registered between 2011 and 2017 was retrieved from the INCA-HRC according to the municipality of residence. Cities that did not have any case of cancer within the period of study were set at zero frequency of cases but were not excluded from the analysis. The following cancer sites (C-00 to C-10) were considered: lip, base of 
tongue, tongue, gingiva, floor of the mouth, palate, other unspecified parts of the mouth, parotid gland, other major salivary glands, tonsils, and oropharynx. The frequency of hospitalized patients with cancer located primarily in the lip and oral cavity (C-00 to C-06), salivary glands (C-07 to C-09) and oropharynx (C-10) was also retrieved from the INCA-HRC. All types of lesions were included, regardless of the degree of staging. A preliminary analysis of cancer data revealed that $90.2 \%$ of the cases corresponded to cases of squamous cell carcinoma.

The independent variables comprised socioeconomic information regarding the Gini coefficient of inequality, municipal Human Development Index (MHDI), inadequate basic sanitation rate (percentage of residences without water and sewage supply within the city), employment rate for individuals older than 18 years of age (percentage of employed individuals above 18 years old), illiteracy rate for individuals aged 15 years old or older (percentage of individuals above 15 years who do not know to write and read), and expected years of schooling (average years of schooling expected for a population). Data were obtained from the panel of socioeconomic indicators of Brazilian cities available at the Human Development Atlas of Brazil (http://atlasbrasil.org.br), which is linked to the United Nations Development Program (UNDP). These data correspond to the year 2010 .

The data were tabulated and analyzed using IBM Statistical Package for Social Sciences (IBMSPSS, v. 24, IBM, Chicago, USA). Bivariate correlations between dependent and independent variables were obtained using Spearman's correlation test $(\mathrm{p}<0.05)$. Bivariate and multivariate Poisson regressions were performed considering the number of diagnoses of mucosal changes and the number of hospitalized patients with oral and oropharyngeal cancer as dependent variables. The number of inhabitants in the Brazilian cities (2010 population, according to http://atlasbrasil. org.br) was used to weight the effect of multivariate regressions. All independent variables were included in the crude multivariate Poisson regression model, followed by a stepwise backward approach. Only variables with a $p$-value $<0.20$ were included in the adjusted multivariate Poisson regression model.
Variables with a p-value $<0.05$ in the adjusted model were considered statistically significant. The incident rate ratio (IRR) and confidence interval $(95 \% \mathrm{CI})$ were obtained for the crude and adjusted models. Regression coefficient B was used to estimate the effect of each independent variable on the dependent variable, considering $\mathrm{p}<0.05$.

Adjusted multivariate Poisson regression models were also obtained for each group of cancer sites using similar modeling and adjustment approaches. The number of hospitalized patients with cancer in the lip and oral cavity (C-00 to C-06), salivary glands (C-07 to C-09) and oropharynx (C-10) were analyzed according to the independent variables under study by using the population size as the weighting effect and the stepwise backward modeling approach.

The procedures for the diagnosis of mucosal changes and the number of hospitalized patients with oral and oropharyngeal cancer were spatially distributed according to the cartographic database of the Brazilian territory (available at http://datasus. saude.gov.br/cadastros-nacionais/294-dowloadmapas-tabwin). The total number of records for the period was exported to the cartographic database according to the code for each municipality. The distribution considered the stratification of values into quartiles. The free software Tabwin/DATASUS was used to map the frequency distribution.

\section{Results}

The number of cities that registered diagnoses of oral mucosal changes between 2011 and 2015 was 3,815 (68.6\%). Between 2011 and 2017, 4,252 cities (76.4\%) registered at least one case of oral and oropharyngeal cancer involving hospitalization. The descriptive data for cities included in the multivariate analysis are presented in Table 1.

Cities without data for "Inadequate basic sanitation rate" and "Illiteracy rate for individuals 15 years of age or older" were excluded from the analysis. The final sample consisted of 5008 cities. Bivariate correlation analysis showed that the number of diagnoses of oral mucosal changes in primary healthcare had a significant correlation $(p<0.05)$ with the number of hospitalized patients with oral and oropharyngeal 
Diagnosis of mucosal changes and hospitalized oral cancer patients in Brazil: influence of socioeconomic factors

Table 1. Descriptive data of dependent, independent and weight variables considered for analysis.

\begin{tabular}{|c|c|c|c|c|c|}
\hline Variables & $\mathrm{n}$ & mean & SD & $\min$. & $\max$ \\
\hline \multicolumn{6}{|l|}{ Dependent variables } \\
\hline Diagnosis of oral mucosal changes (absolute frequency) & 5008 & 76.78 & 473.63 & 0 & 17690 \\
\hline $\begin{array}{l}\text { Hospitalized patients with oral and oropharyngeal cancer (absolute } \\
\text { frequency) }\end{array}$ & 5008 & 9.92 & 61.83 & 0 & 3723 \\
\hline \multicolumn{6}{|l|}{ Cancer cases according to primary sites } \\
\hline Oral cavity (C-00 to C-06) (absolute frequency) & 5008 & 8.74 & 50.65 & 0 & 2649 \\
\hline Salivary Glands (C-07 to C-09) (absolute frequency) & 5008 & 2.01 & 12.74 & 0 & 690 \\
\hline Oropharynx (C-10) (absolute frequency) & 5008 & 2.45 & 15.73 & 0 & 799 \\
\hline \multicolumn{6}{|l|}{ Covariate independent variables } \\
\hline Gini's inequality coefficient & 5008 & 0.50 & 0.06 & 0.29 & 0.80 \\
\hline Municipality's Human Development Index & 5008 & 0.65 & 0.07 & 0.42 & 0.85 \\
\hline Inadequate basic sanitation rate (\%) & 5008 & 9.99 & 13.08 & 0.01 & 85.36 \\
\hline Employment rate for individuals over 18 years of age (\%) & 5008 & 62.93 & 9.08 & 21.18 & 95.60 \\
\hline Illiteracy rate for individuals 15 years of age or older (\%) & 5008 & 16.79 & 9.91 & 44.40 & 0.95 \\
\hline Expected years of schooling (years) & 5008 & 9.38 & 1.07 & 4.34 & 12.83 \\
\hline \multicolumn{6}{|l|}{ Scale Weight } \\
\hline Population (absolute frequency) & 5008 & $36,440.55$ & $212,484.47$ & 805 & $11,253,503$ \\
\hline
\end{tabular}

$\mathrm{n}$ : sample size considered for analysis; SD: standard deviation; min.: minimum value; max.: maximum value.

Table 2. Spearman's bivariate correlation matrix for dependent and independent variables.

\begin{tabular}{|c|c|c|c|c|c|c|}
\hline \multirow[t]{2}{*}{ Variables } & \multicolumn{3}{|c|}{$\begin{array}{c}\text { Diagnosis of oral mucosal } \\
\text { changes }\end{array}$} & \multicolumn{3}{|c|}{$\begin{array}{l}\text { Hospitalized patients with ora } \\
\text { and oropharyngeal cancer }\end{array}$} \\
\hline & $\rho$ & $\mathrm{p}$-value & $\mathrm{n}$ & $\rho$ & $\mathrm{p}$-value & $\mathrm{n}$ \\
\hline Diagnosis of mucosal changes in primary care & - & - & 5008 & 0.304 & $<0.001$ & 5008 \\
\hline Hospitalized patients with oral and oropharyngeal cancer & 0.304 & $<0.001$ & 5008 & - & - & 5008 \\
\hline Gini's inequality coefficient & 0.090 & $<0.001$ & 5008 & -0.067 & $<0.001$ & 5008 \\
\hline Municipality's Human Development Index & 0.068 & $<0.001$ & 5008 & 0.329 & $<0.001$ & 5008 \\
\hline Inadequate basic sanitation rate & 0.030 & 0.037 & 5008 & 0.233 & $<0.001$ & 5008 \\
\hline Employment rate for individuals over 18 years of age & 0.016 & 0.251 & 5008 & 0.194 & $<0.001$ & 5008 \\
\hline Illiteracy rate for individuals 15 years of age or older & 0.018 & 0.206 & 5008 & 0.308 & $<0.001$ & 5008 \\
\hline Expected years of schooling & 0.009 & 0.505 & 5008 & 0.112 & $<0.001$ & 5008 \\
\hline
\end{tabular}

$\rho$ : Spearman's correlation coefficient; $p$-value $<0.05$ indicates a statistically significant correlation; N: sample size considered for analysis.

cancer and with the Gini coefficient of inequality, MHDI and inadequate basic sanitation (Table 2). The number of hospitalized patients with oral and oropharyngeal cancer reported by the INCA showed a statistically significant correlation $(p<0.05)$ with all studied variables (Table 2).

Multivariate Poisson regression confirmed that Gini's inequality coefficient, the MHDI and the number of hospitalized patients with oral and oropharyngeal cancer had a statistically significant association $(p<0.05)$ with the number of diagnoses of oral mucosal changes (Table 3). A higher frequency of diagnoses of mucosal changes was observed in cities with higher inequality, a higher MHDI, and a higher frequency of hospitalized patients with oral and oropharyngeal cancer.

According to the multivariate regression model (Table 4), cities with higher inequality, a higher 
Table 3. Bivariate and multivariate Poisson regressions to determine the effect of independent variables (socioeconomic factors) on the frequency of oral mucosal changes, as based on the records of primary care services of the Brazilian public healthcare system.

\begin{tabular}{|c|c|c|c|c|c|c|c|c|c|c|}
\hline \multirow{2}{*}{ Variables } & \multicolumn{2}{|c|}{ Bivariate } & \multicolumn{4}{|c|}{ Crude multivariate model } & \multicolumn{4}{|c|}{ Adjusted multivariate model } \\
\hline & $p$-value & IRR (95\%CI) & B & $p$-value & IRR & $95 \% \mathrm{Cl}$ & B & $p$-value & IRR & $95 \% \mathrm{Cl}$ \\
\hline $\begin{array}{l}\text { Gini's inequality } \\
\text { coefficient }\end{array}$ & $<0.001$ & $\begin{array}{c}6.17 \times 10^{7} \\
\left(1.51 \times 10^{7}-\right. \\
\left.2.52 \times 10^{9}\right)\end{array}$ & 12.484 & 0.001 & 264107.53 & $233.59-29.86 \times 10^{7}$ & 11.614 & $<0.001$ & 110610.14 & $998.65-1.22 \times 10^{7}$ \\
\hline $\begin{array}{l}\text { Municipality's } \\
\text { Human } \\
\text { Development } \\
\text { Index }\end{array}$ & $<0.001$ & $\begin{array}{l}1.37 \times 10^{11} \\
\left(2.59 \times 10^{6}-\right. \\
\left.2.29 \times 10^{15}\right)\end{array}$ & 8.844 & 0.246 & 6.935 .501 & $0.002-21.38 \times 10^{9}$ & 11.298 & $<0.001$ & 80699.15 & $509.48-5.27 \times 10^{6}$ \\
\hline $\begin{array}{l}\text { Inadequate } \\
\text { basic sanitation }\end{array}$ & 0.065 & $\begin{array}{c}1.233 \\
(0.987-1.540)\end{array}$ & 0.006 & 0.892 & 1.006 & $0.922-1.097$ & & & & \\
\hline $\begin{array}{l}\text { Employment rate } \\
\text { for individuals } \\
\text { over } 18 \text { years } \\
\text { of age }\end{array}$ & $<0.001$ & $\begin{array}{c}1.069 \\
(1.031-1.107)\end{array}$ & -0.021 & 0.479 & 0.980 & $0.925-1.037$ & & & & \\
\hline $\begin{array}{l}\text { Expected years } \\
\text { of schooling }\end{array}$ & 0.001 & $\begin{array}{c}1.789 \\
(1.262-2.536)\end{array}$ & 0.191 & 0.578 & 1.210 & $0.618-2.372$ & & & & \\
\hline $\begin{array}{l}\text { Illiteracy rate } \\
\text { for individuals } \\
15 \text { years of age } \\
\text { or older }\end{array}$ & 0.017 & $\begin{array}{c}1.333 \\
(1.052-1.688)\end{array}$ & 0.023 & 0.617 & 1.023 & $0.935-1.119$ & & & & \\
\hline $\begin{array}{l}\text { Hospitalized } \\
\text { patients with } \\
\text { oral and } \\
\text { oropharyngeal } \\
\text { cancer }\end{array}$ & $<0.001$ & $\begin{array}{c}1.001 \\
(1.001-1.001)\end{array}$ & 0.001 & $<0.001$ & 1.001 & $1.001-1.001$ & 0.001 & $<0.001$ & 1.001 & $1.001-1.001$ \\
\hline
\end{tabular}

B: regression coefficient; SE: standard error; p-value: statistical significance; IRR: incident rate ratio; 95\%Cl: 95\% confidence interval (upper-lower).

inadequate basic sanitation rate, lower expected years of schooling and a higher illiteracy rate are likely to present a higher frequency of cancer cases (Table 4). The diagnosis of oral changes in primary care was statistically significant, but it did not significantly affect the number of cancer cases (95\%CI: 1,000-1,000). Income concentration and worse socioeconomic conditions are likely associated with an increase in the number of hospitalized patients with oral and oropharyngeal cancer in Brazil.

The effect of socioeconomic variables on the frequency of cancer primarily located in the lip and oral cavity, salivary glands and oropharynx is shown in Table 5. Similar to that observed in Table 4, higher inequality, a higher inadequate basic sanitation rate, lower expected years of schooling and a higher illiteracy rate were associated with a higher frequency of cancer cases within those cancer sites (Table 5). Major effects were observed for the Gini inequality coefficient and expected years of schooling.

Many cities in Brazil did not register diagnoses of mucosal changes (Figure 1A). A higher frequency of cancer was registered along the coast, mainly for cities from the Northeast, Southeast and South regions (Figure 1B). The regional distribution of cancer cases according to cancer sites is presented in Figure 2 (A to C). A lower frequency of cases was reported for the North and Central-West regions.

\section{Discussion}

The results from this study suggest that socioeconomic aspects have a significant effect on access to preliminary diagnosis and hospital admission of patients with oral and oropharyngeal cancer in Brazil. Socioeconomic characteristics of Brazilian cities should be interpreted as a modulating factor for the frequency of diagnoses of oral mucosal changes and for the number of cancer cases involving hospitalization. Factors related to the fluctuation of primary care services are diverse, ${ }^{18,20}$ and etiological aspects of oral and oropharyngeal cancer have been extensively discussed. ${ }^{4,7,9,10,11}$ The results from this study suggest that less privileged and 

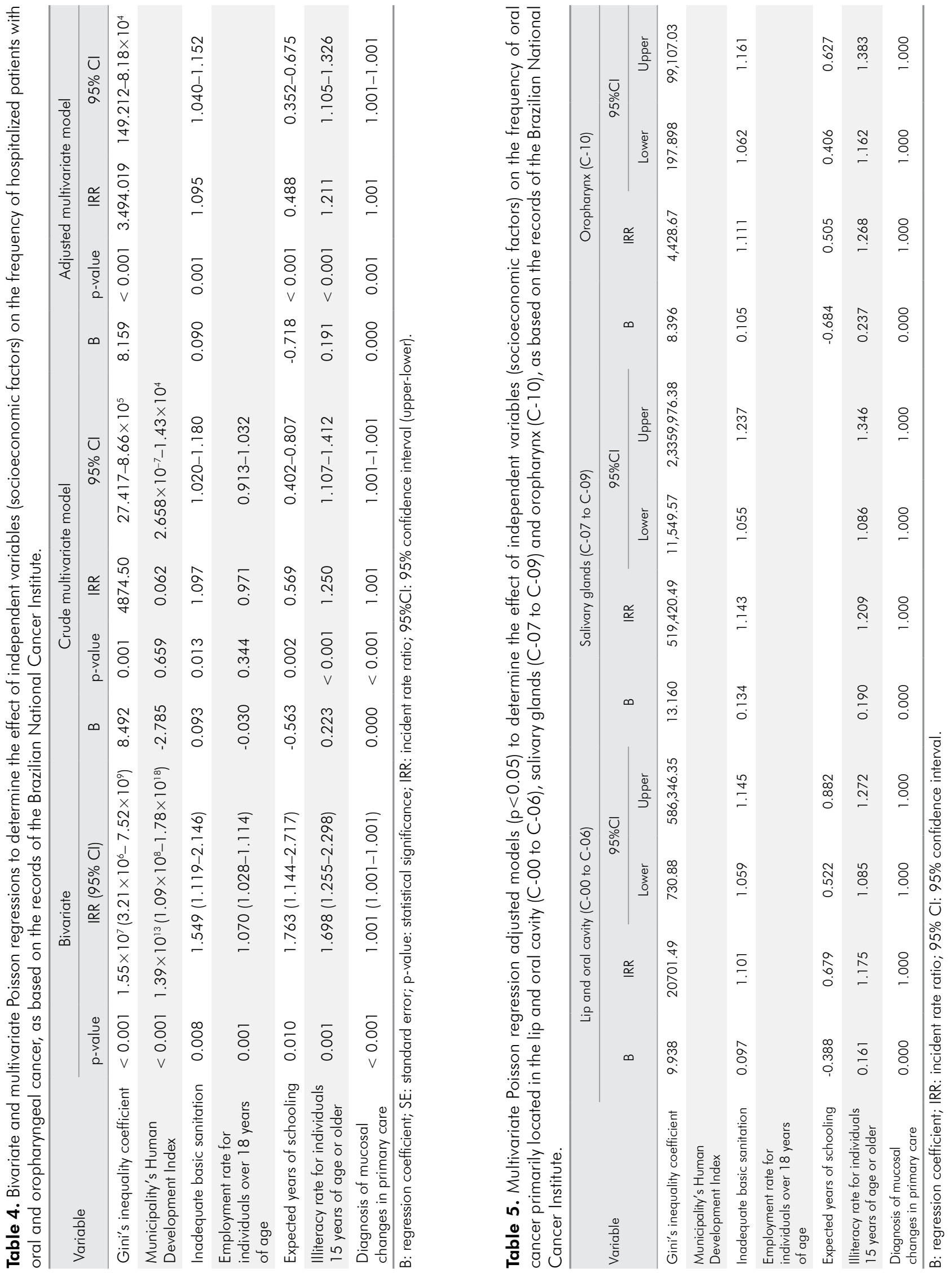


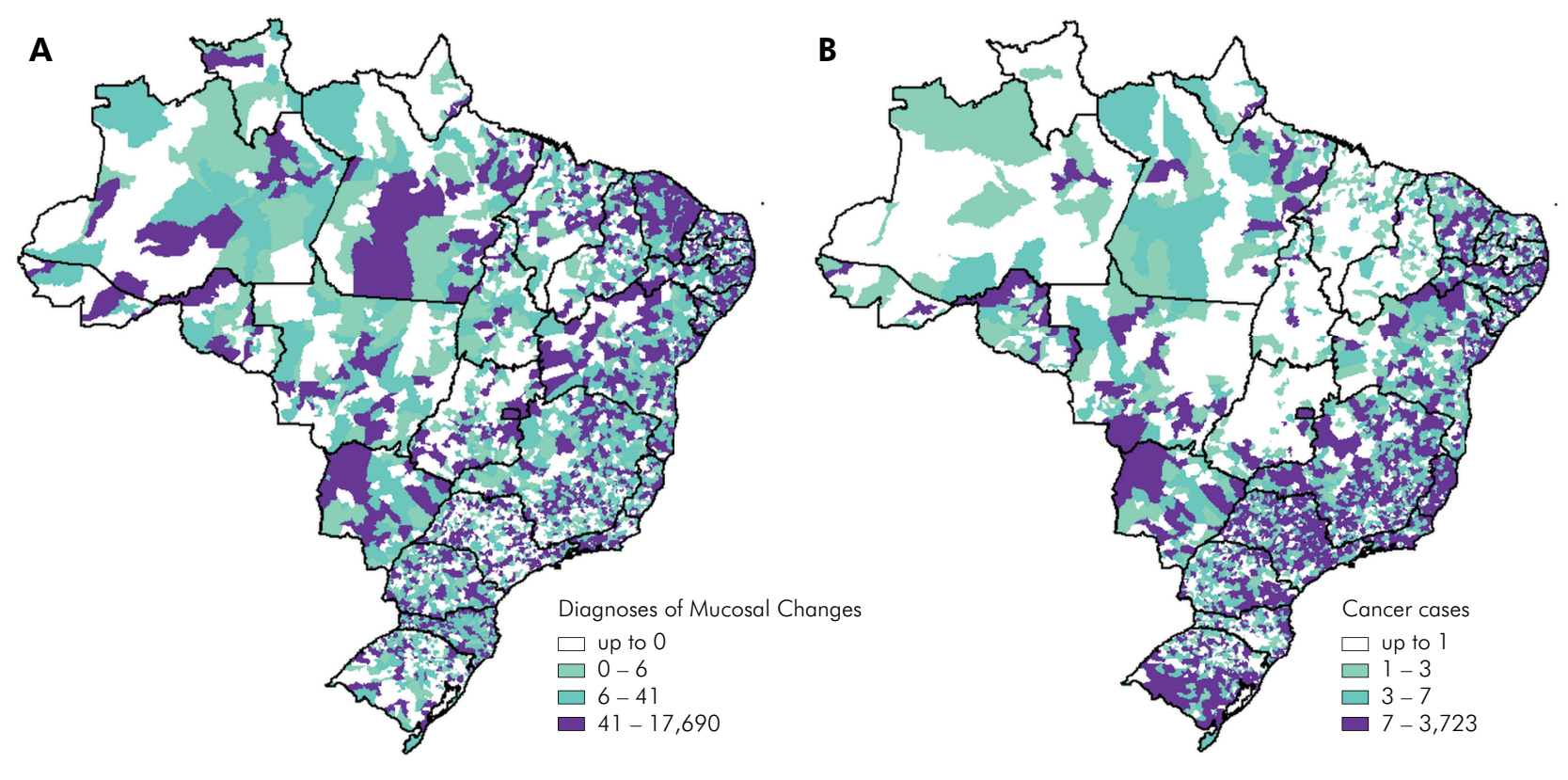

Figure 1. A: Frequency distribution into quartiles of diagnoses of mucosal changes among Brazilian cities. B: Frequency distribution into quartiles of hospitalized patients with oral and oropharyngeal cancer among Brazilian cities.
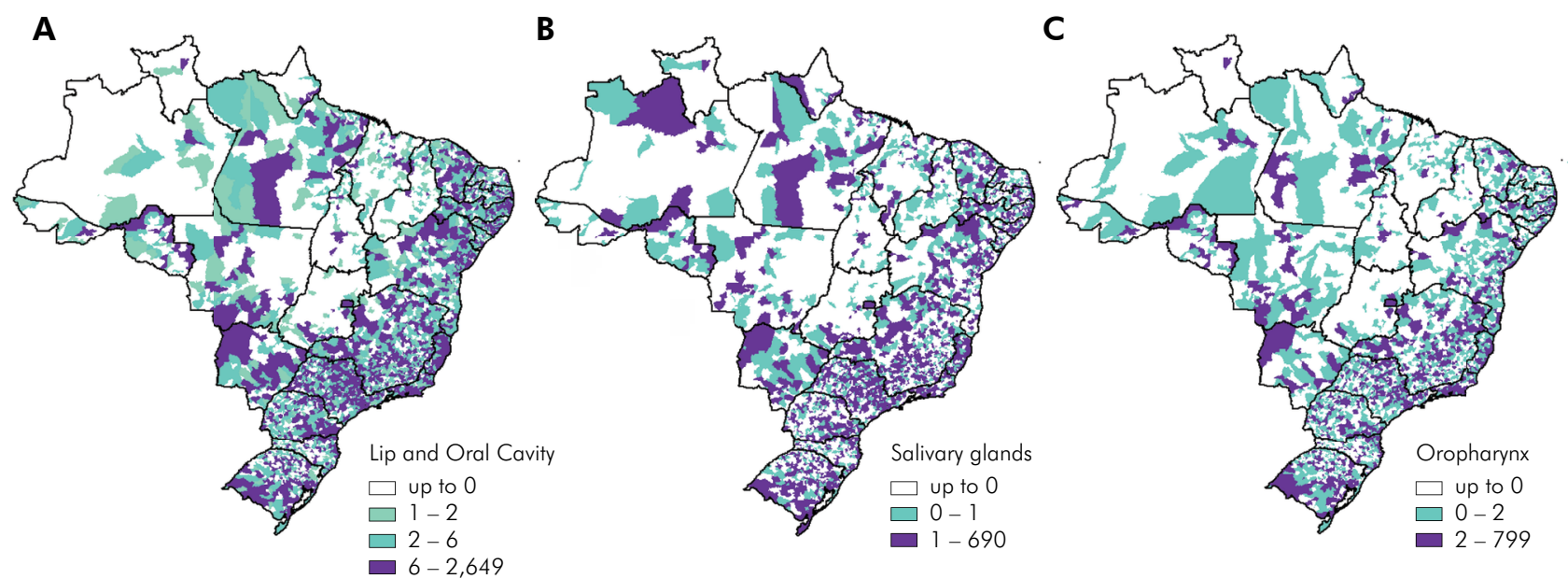

Figure 2. Frequency distribution into quartiles of hospitalized patients with cancer in the lip and oral cavity (A), salivary glands (B) and oropharynx (C) among Brazilian cities.

vulnerable populations are less likely to have access to preliminary diagnosis and to hospital treatment. Nevertheless, the results should be interpreted with care, as the study was based on a secondary source of information under a cross-sectional design.

The offer of diagnostic procedures for oral mucosal changes was initially proposed by the Brazilian Ministry of Health to encourage the monitoring and planning of policies and actions aimed at health promotion, prevention and early diagnosis in primary care. However, the Brazilian primary care information system has undergone recent changes, and many professionals still do not know it thoroughly or have not received the training necessary to understand the nature of this type of notification..$^{21}$ This scenario can lead to inefficient registration, even though this source of data is still reliable for monitoring Brazilian public health services. ${ }^{22}$ 
To our knowledge, data for the diagnosis of oral mucosal changes have not been used before for discussing the access of a population to oral cancer preliminary diagnosis. Data from this study suggest that more unequal and more developed cities may also have a greater number of records of diagnoses of oral mucosal changes. This is probably due to a better-structured network of health care services, mainly in larger and more populated cities $^{23}$. Although the frequency of diagnoses of oral mucosal changes seems well distributed among the Brazilian macroregions, many cities did not register any case of oral mucosal change between 2011 and 2015.

It is important to highlight that an absence of registered diagnosis of oral mucosal changes does not mean an absence of cases, a lower frequency of oral mucosal examination, or inefficiency of the healthcare network. Indeed, it is probably due to a lack of registration or low coverage of primary care within the municipality. ${ }^{23,24}$ Overall, the frequency of diagnoses of oral mucosal changes might not be reliable for monitoring the frequency of early diagnosis of oral cancer. Nevertheless, this parameter is unique and may provide some evidence regarding population access to oral mucosal examination as a preventive measure for oral cancer in Brazilian primary care.

Although statistically significant bivariate correlations between the number of diagnoses of oral mucosal changes and the frequency of hospitalized cancer cases were detected in the present study, it is not possible to affirm that those variables are strictly associated. In fact, adjusted multivariate models demonstrated very limited associations between those variables.

The frequency of hospitalization of patients with oral and oropharyngeal cancer obtained from the INCA-HRC may not be considered as a measure of cancer prevalence in Brazil. Although the absolute frequency of cases is not the best parameter for evaluation, it is uniquely related to the cancer frequency in Brazil. The INCA-HRC does not currently provide age-standardized rates for each municipality in different periods of time, which would be recommended. ${ }^{1,2}$ Thus, the data used in this study correspond to the absolute frequencies of hospitalized patients retrieved from the INCA-HRC. To reduce the influence of hospital-based data, the authors used the population size to weight the effects, in addition to harvesting the number of cases according to the municipality of residence.

The absence of records should not be interpreted as a lack of realistic cases because not all cases of cancer in Brazil are linked to the INCA-HRC. For example, the lower frequency of cases recorded for the North and Central-West regions may be associated with a lower proportion of cancer treatment units, which are more concentrated in the Northeast (19.1\%), Southeast (46.3\%) and South (23.5\%) regions. ${ }^{25}$ Therefore, it is important to assume that eventually, cases of cancer may not be registered due to the limited access of the population to health services.

The healthcare network for cancer patients in Brazil is preferentially part of the public healthcare system, and it is mostly located in capitals and better-developed centers. ${ }^{25,26}$ The absence of a statistical association between the MHDI and the frequency of hospitalized cases of cancer is probably because we analyzed data based on the municipality of residence. Nevertheless, other relevant socioeconomic aspects were significantly associated with a higher frequency of cases, irrespective of the primary site of cancer.

The effect of socioeconomic factors on the frequency of oral cancer primarily located in the lip and oral cavity (C-00 to C-06), salivary glands (C-07 to C-09) and oropharynx (C-10) is novel, as previous studies have analyzed those different primary sites as a single entity., $5,13,17,19$ This study found similar socioeconomic factors associated with the frequency of hospitalized patients with cancer in the lip and oral cavity, salivary glands and oropharynx. Overall, the inequality coefficient was the most significant socioeconomic variable, considering both the general number of hospitalized cancer patients and those stratified by primary site.

The impact of socioeconomic inequality has been discussed in a previous meta-analysis, which considered unjust differences regarding monthly household income, occupational social class and educational level. ${ }^{12}$ According to this previous review, socioeconomic inequalities are potentially associated with lifestyle risk factors in a complex manner. ${ }^{12}$ Data from our study confirm that higher education and access to better living conditions (access to water and 
sewage supply) have a general impact on the frequency of hospitalization of patients with oral cancer.

The influence of the MHDI on oral cancer rates in Brazil varies; some found an inversely proportional effect, ${ }^{5,13,17}$ whereas others suggest a positive association ${ }^{27}$. In the present study, despite showing a positive correlation with hospitalized patients with oral and oropharyngeal cancer in bivariate analysis, the effect of the variable MHDI was lower than that of other socioeconomic factors that seem to have greater strength of association from the perspective of Brazilian cities. Although they may be considered developed, many cities have strong income concentration, segregation and social inequalities. ${ }^{28}$ In this sense, the factors included in the analysis comprise aspects such as education and income, which themselves are part of the MHDI. Therefore, exclusion of the MHDI from the adjusted model does not suggest a problematic analysis or a collinearity issue.
The results and inferences of the present study should be analyzed carefully, considering the cross-sectional design and the secondary data source. Regardless, the data from this study are representative of the Brazilian population and are from all of its cities for the last decade. Oral and oropharyngeal cancer is a complex disease, and several etiological and modifying factors must be taken into account. Further analyses of other countries and socioeconomic contexts may corroborate the findings of this study.

\section{Conclusion}

A higher frequency of diagnoses of mucosal changes was observed in more developed cities and those with inequality. Greater inequality and worse socioeconomic conditions are associated with a higher frequency of hospitalized patients with oral and oropharyngeal cancer in Brazil.

\section{References}

1. Bray F, Ferlay J, Soerjomataram I, Siegel RL, Torre LA, Jemal A. Global cancer statistics 2018: GLOBOCAN estimates of incidence and mortality worldwide for 36 cancers in 185 countries. CA Cancer J Clin. 2018 Nov;68(6):394-424. https://doi.org/10.3322/caac.21492

2. World Health Organization - WHO. Global Cancer Observatory. International Agency for Research on Cancer. Estimated number of new cases in 2018, lip, oral cavity, oropharynx, salivary glands, both sexes, all ages. [cited 2020 May 10] Available from: https://gco.iarc.fr/today/home

3. Warnakulasuriya S. Global epidemiology of oral and oropharyngeal cancer. Oral Oncol. 2009 Apr-May;45(4-5):309-16. https://doi.org/10.1016/i.oraloncology.2008.06.002

4. Santos HB, Santos TK, Paz AR, Cavalcanti YW, Nonaka CF, Godoy GP, et al. Clinical findings and risk factors to oral squamous cell carcinoma in young patients: A 12-year retrospective analysis. Med Oral Patol Oral Cir Bucal. 2016 Mar;21 (2):e151-6. https://doi.org/10.4317/medoral.20770

5. Sakamoto AJ, Brizon VS, Bulgareli JV, Ambrosano GM, Hebling E. Influence of municipal socioeconomic indices on mortality rates for oral and oropharyngeal cancer in older adults in the State of São Paulo, Brazil. Rev Bras Epidemiol. 2019 Mar;22:e190013. https://doi.org/10.1590/1980-549720190013

6. Majchrzak E, Szybiak B, Wegner A, Pienkowski P, Pazdrowski J, Luczewski L, et al. Oral cavity and oropharyngeal squamous cell carcinoma in young adults: a review of the literature. Radiol Oncol. 2014 Jan;48(1):1-10. https://doi.org/10.2478/raon-2013-0057

7. Warnakulasuriya S. Living with oral cancer: epidemiology with particular reference to prevalence and life-style changes that influence survival. Oral Oncol. 2010 Jun;46(6):407-10. https://doi.org/10.1016/i.oraloncology.2010.02.015

8. Warnakulasuriya S. Causes of oral câncer: an appraisal of controversies. Br Dent J. 2009 Nov;207(10):471-5. https://doi.org/10.1038/sj.bdj.2009.1009

9. Bezerra NV, Leite KL, Medeiros MM, Martins ML, Cardoso AM, Nonaka CF, et al. Advanced-stage tongue and mouth floor cancer is related to tobacco and alcohol abuse. J Public Health. 2018 Apr;26(1):151-6. https://doi.org/10.1007/s10389-017-0859-3

10. Bezerra NV, Leite KL, Medeiros MM, Martins ML, Cardoso AM, Alves PM, et al. Impact of the anatomical location, alcoholism and smoking on the prevalence of advanced oral cancer in Brazil. Med Oral Patol Oral Cir Bucal. 2018 May;23(3):e295-301. https://doi.org/10.4317/medoral.22318

11. Bravi F, Bosetti C, Filomeno M, Levi F, Garavello W, Galimberti S, et al. Foods, nutrients and the risk of oral and pharyngeal cancer. Br J Cancer. 2013 Nov;109(11):2904-10. https://doi.org/10.1038/bjc.2013.667 
Diagnosis of mucosal changes and hospitalized oral cancer patients in Brazil: influence of socioeconomic factors

12. Conway DI, Petticrew M, Marlborough H, Berthiller J, Hashibe M, Macpherson LM. Socioeconomic inequalities and oral cancer risk: a systematic review and meta-analysis of case-control studies. Int J Cancer. 2008 Jun;122(12):2811-9. https://doi.org/10.1002/iic.23430

13. Moi GP, Silva AM, Galvão ND, Meneghim MC, Pereira AC. Spatial analysis of the death associated factors due oral cancer in Brazil: an ecological study. BMC Oral Health. 2018 Jan;18(1):14. https://doi.org/10.1186/s12903-018-0473-y

14. Shin JY, Yoon JK, Shin AK, Diaz AZ. The influence of insurance status on treatment and outcomes in oral cavity cancer: an analysis on 46,373 patients. Int J Oral Maxillofac Surg. 2018 Oct;47(10):1250-7. https://doi.org/10.1016/i.ijom.2018.03.022

15. Kwok J, Langevin SM, Argiris A, Grandis JR, Gooding WE, Taioli E. The impact of health insurance status on the survival of patients with head and neck cancer. Cancer. 2010 Jan;116(2):476-85. https://doi.org/10.1002/cncr.24774

16. Johnson NW, Warnakulasuriya S, Gupta PC, Dimba E, Chindia M, Otoh EC, et al. Global oral health inequalities in incidence and outcomes for oral cancer: causes and solutions. Adv Dent Res. 2011 May;23(2):237-46. https://doi.org/10.1177/0022034511402082

17. Ferreira MA, Gomes MN, Michels FA, Dantas AA, Latorre MR. [Social inequality in morbidity and mortality from oral and oropharyngeal cancer in the city of São Paulo, Brazil: 1997-2008]. Cad Saude Publica. 2012 Sep;28(9):1663-73. Portuguese. https://doi.org/10.1590/S0102-311X2012000900006

18. Viacava F, Oliveira RA, Carvalho CC, Laguardia J, Bellido JG. SUS: supply, access to and use of health services over the last 30 years. Cien Saude Colet. 2018 Jun;23(6):1751-62. https://doi.org/10.1590/1413-81232018236.06022018

19. Cunha AR, Prass TS, Hugo FN. Mortality from oral and oropharyngeal cancer in Brazil: impact of the National Oral Health Policy. Cad Saude Publica. 2019 Nov;35(12):e00014319. https://doi.org/10.1590/0102-311x00014319

20. Noro LR, Landim JR, Martins MC, Lima YC. The challenge of the approach to oral cancer in primary health care. Cien Saude Colet. 2017 May;22(5):1579-87. https://doi.org/10.1590/1413-81232017225.12402015

21. Gava M, Ferreira LS, Palhares D, Mota EL. Incorporation of information technology in Primary Care of SUS in North-eastern Brazil: expectations and experiences. Cien Saude Colet. 2016 Mar;21(3):891-902. https://doi.org/10.1590/1413-81232015213.01062015

22. Lopes FR, Monteiro KS, Santos S. How data provided by the Brazilian information system of primary care have been used by researchers. Health Informatics J. 2020 Sep;26(3):1617-30: https://doi.org/10.1177/1460458219882273

23. Casotti E, Contarato PC, Fonseca ABM, Borges PKO, Baldani MH. Atenção em Saúde Bucal no Brasil: uma análise a partir da Avaliação Externa do PMAQ-AB. Saúde Debate. 2014; 38(esp):140-57.

24. Martins RC, Reis CM, Machado ATM, Amaral JH, Werneck MA, Abreu MH. Relationship between Primary and Secondary Dental Care in Public Health Services in Brazil. PLoS One. 2016 Oct;11(10):e0164986. https://doi.org/10.1371/journal.pone.0164986

25. Silva MJ, O'Dwyer G, Osorio-de-Castro CG. Cancer care in Brazil: structure and geographical distribution. BMC Cancer. 2019 Oct;19(1):987. https://doi.org/10.1186/s12885-019-6190-3

26. Grabois MF, Oliveira EX, Carvalho MS. [Access to pediatric cancer care in Brazil: mapping origin-destination flows]. Rev Saude Publica. 2013 Apr;47(2):368-78. Portuguese. https://doi.org/10.1590/S0034-8910.2013047004305 PMID:24037365

27. Borges DM, Sena MF, Ferreira MA, Roncalli AG. [Mortality for oral cancer and socioeconomic status in Brazil]. Cad Saude Publica. 2009 Feb;25(2):321-7. Portuguese. https://doi.org/10.1590/S0102-311X2009000200010

28. Herrera-Serna BY, Lara-Carrillo E, Toral-Rizo VH, Amaral RC, Aguilera-Eguía RA. Relationship between the Human Development Index and its components with oral cancer in Latin America. J Epidemiol Glob Health. 2019 Dec;9(4):223-32. https://doi.org/10.2991/jegh.k.191105.001 